\title{
The emergence of digitalisation in the context of health care
}

\author{
Marius Mihailescu \\ Uppsala University, Campus \\ Gotland, Sweden \\ marius.mihailescu@im.uu.se
}

\author{
Daniela Mihailescu \\ Uppsala University, Campus \\ Gotland, Sweden \\ daniela.mihailescu@im.uu.se
}

\begin{abstract}
Digitisation of medical records by means of Electronic Patient Record (EPR) systems promises to improve the overall quality of health care. However, studies show that the outcome of their use is mixed. Derived from a critical realism lens the morphogenetic approach is used to understand and explain how does digitalisation emerge in health care settings. We draw on a longitudinal case study of a hospital that implemented an EPR system. Interviews and observations were used as data collection techniques. The initial analysis identified three tentative generative mechanisms: data-sharing, process-streamlining, and connectivity mechanisms which help to describe and explain the emergence of digitalisation in health care context. By using the morphogenetic approach, two grains are seen to accrue: the critical role of digital materiality in organisational change and clarity about the interplay between the materiality of technology (an emergent property of structure) and agential reflexivity (an emergent property of agency).
\end{abstract}

\section{Introduction}

The implementation of Electronic Patient Record (EPR) systems has increased significantly in the last decades [42]. EPR is frequently regarded as an essential solution to the many challenges faced by health care providers and the health care sector in general [11].

The digitalisation of patient records, i.e., the conversion of paper-based records into a digital form by applying digitising technology, enables spatial separation between actors and physical artefacts by using digitising technologies [41]. The EPR is considered by many as an important strategy to meet the challenges facing health care sector [2]. It is expected to improve the overall quality of health care, including an increase in patient safety [15]. These outcomes are attributed to reducing redundant documentation and paperwork, improving the efficiency of workflows [37], facilitating better integration across functional silos, providing real time access to patient information, reducing risks and saving time [30]. Despite the significant potential for performance gains from EPR system, many EPR systems implementations fail to live up to expectations [22], and the anticipated improvements do not always materialise [2]. Some of the literature suggests that the use of EPR systems has had detrimental effects on patient safety [24; 7]; on time savings [26]; and those that are successful are characterised by delays and cost escalation [8].

Current studies reveal contradictory findings and provide a fragmented understanding of health care digitalisation. Consequently, we need to develop theories that are capable of accounting for the conditions under which certain causal powers, i.e., generative mechanisms associated with health care digitalisation are actualised and with what consequences. To develop such a conceptual framework, we draw on the digitalisation literature and Archer's morphogenetic approach [3; 5] to explain organisational change over time.

While digitalisation, refers to the conversion of analogue data into digital data by applying digitising technology (e.g., an EPR), [41], digitalisation, refers to the change of socio-material structures [43], e.g., new work practices, new physical work arrangements and new organisational and/or social structures. Structure refers to "a set of internally related objects or practices" [38 p. 92] with emergent properties [3; 39].

In this study digitalisation is regarded as a form of IT-enabled change and digitisation is viewed as a technical requirement of the digitalisation process. For instance, in an analogue world, devices, storage media and transmission formats are specific to a service, thus limiting the reuse of the data (e.g., a paper-based medical record is limited in its application). By decoupling information from its physical storage (e.g., an electronic medical record), digitalisation unleashes the generative potential of recombining content with different applications and devices (e.g., using the same medical record for ward rounds and real-time analytics), thus reshaping work practices and social structures. 
To explain how digitalisation emerges requires that we identify its generative mechanisms. According to Bhaskar [12], a generative mechanism is a causal structure that might generate events. For example, the interplay between the materiality of technology (an emergent property of structure) and agential reflexivity (an emergent property of agency), may or may not generate organisational change associated with the conversion of analogue data into digital formats and the work practices change this requires. Reflexivity is defined as the ability to reflect upon itself and its actions [4].

The morphogenetic approach, which falls under the $\mathrm{CR}$ umbrella, enables us to examine the interplay between structure and agency over time. According to Elster [19], generative mechanisms are supposed to play a significant role in developing mid-range theories. To develop such a mid-range theory of digitalisation in health care settings, we adopted Archer's [6] definition of generative mechanisms and defined them as the unobservable and emergent causal powers that arise from the interplay between structural proprieties and properties of agency through which observable or unobservable events are produced.

To understand digitalisation and explain how transformational outcomes are produced, our research seeks to answer the following question: How does digitalisation emerge in a health care setting?

To address the research question, we draw on an extensive longitudinal case study [18] of a hospital that implemented an EPR system. To gain the insights necessary to uncover generative mechanisms, their interplay and the contextual factors that generate contingent outcomes [17], we draw on an extensive and rich empirical data using multiple data collection techniques: interviews, participant observation and documents produced at the field site. Causal and crosscomparative analyses were then employed to identify generative mechanisms of digitalisation.

By focusing on the generative mechanisms that underlie this technology-enabled change this research adds to our knowledge of the digitalisation of health care. It also develops theoretical rigour around the notion of generative mechanisms, which is gaining popularity in IS research [27]. Another contribution is to the growing body of digitalisation and empirical studies in the IS literature seeking to develop a sociomaterial understanding of how organisational change emerge over time [33]. This research also responds to the request for a more explicit consideration of reflexivity in IS research [17]. The morphogenetic approach, used in this research considers the different modes of agential reflexivity and how these might be impacted by the materiality of technology [33].
The rest of the paper is structured as follows: prior literature on digitalisation in health care is briefly presented in Section 2. Section 3 introduces the theoretical basis of the research and provides a brief description of the morphogenetic approach, which informs the conceptual framework used to conceptualise the generative mechanisms of digitalisation. The paper concludes with a description of the research design and presents some initial results.

\section{Background literature}

The digitalisation of health care is considered one of the most compelling answers to the increasing pressures of improving the quality of health care. However, to date, there are few empirical studies on health care digitalisation. Much of the digitalisation research has focused on digital innovation where scholars are primarily concerned with the characteristics, properties [43], design and architecture of digital technology [37; 4] and less with the dynamics of digitalisation that represent organisational changes. As defined in the recent literature, digitalisation is "[t]he transformation of sociotechnical structures that were previously mediated by non-digital artefacts or relationships into ones that are mediated by digitized artefacts and relationships" [43 p. 6]. An important point can be extracted from this definition: there is a significant distinction between digitalisation, a technical process; and digitalisation a socio-material process, i.e., the interplay between the social and the material. The existing literature on digitalisation provides us little insight into the generative mechanisms by which social structures are transformed to take advantage of the decoupling of content from its physical sub-stratum.

IS research has traditionally not addressed the material aspects of technology [36]. Thus, an important starting point for research into digitalisation is to recognise the important role of materiality of technology [35]. Materiality is defined as the properties that enable or constrain people's goals and their interaction with digital technology [31].

The hospital environment is unique and complex, with almost independent health care professionals [28], and strong hierarchical structures [13]. It is also characterised by highly specialised and ad-hoc work processes [42]. Furthermore, health care is information intensive, and the quality of its services is dependent on information being accurate, relevant, integrated and available when needed [23]. Digitalisation of medical records by means of EPR promises to meet those requirements [21]. Despite the increase in digitalisation, thanks to digital technology, e.g., an 
EPR, the results of digitalisation initiatives have often been disappointing, and the literature has provided a fragmented understanding of the mixed results. Additionally, the degree of change (i.e., digitalisation) has been low in the health care sector [40], and the anticipated improvements in performance do not always materialise [2]. Moreover, digitalisation is perceived as time-consuming [25], disruptive and even life threatening [1], generating unpredictable outcomes [2]. This background indicates a need for more research into the generative mechanisms of digitalisation [37]

\section{Theoretical underpinning}

IS research, has traditionally been underpinned by a positivistic and an interpretative perspective. However, there has been growing interest in using a critical realism (CR) perspective [34]. As a philosophy of science, $\mathrm{CR}$ has been argued to generate an understanding of IS as a mediator of organisational change [14] and assist the researcher in describing and explaining the structures and generative mechanisms that produce observable events. In IS research, there is growing interest in the application of CR [16], and particularly Archer's morphogenetic approach [32].

Critical realism assumes a stratified ontology and distinguishes between the real, the actual and the empirical (figure 1), [12].

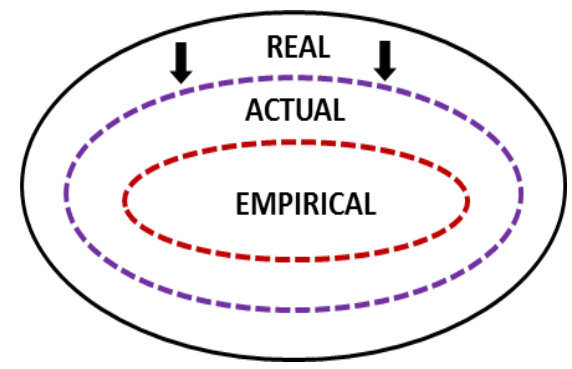

Figure 1. The stratified ontology of CR

The empirical domain is where events are observed and experienced. However, observed events occur in the actual domain. They may or may not be observed at all. Events are generated by mechanism residing in the real domain. The real domain subsumes the domains of the actual and the empirical and consists of underlying objects, their structures and generative mechanisms or powers. The generative mechanisms residing in the real domain exist independently of the patterns of events that they are generating. CR is a philosophy, but its focus is on ontology, not epistemology [39]. Epistemologically, CR focuses on the relationship between generative mechanisms, events and our (empirical) experiences. In CR, causality plays an essential role in describing and explaining how and why the mechanisms generate events (figure 2), [34].

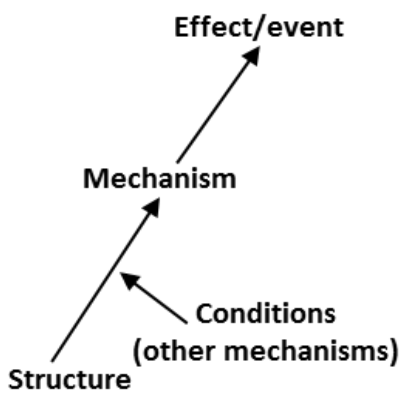

Figure 2. CR view of casualization [39 s. 15]

The morphogenetic approach reflects CR's assumptions and highlights the importance of the material properties of technology. The consideration of materiality helps us to analyse the relationship between materiality of technology and agential reflexivity. Moreover, the consideration of different modes of agential reflexivity helps us to explain how these might be impacted by materiality of technology [33]. Sadly, to date, few empirical IS-studies are using the morphogenetic approach [17].

Structure and agency are ontologically separate, each having relative autonomy but interacting with each other [5]. Structures have emergent properties [39] and are delineated by the resource distribution and the organisational positions that agents occupy as they pursue their interests. Structures shape the situations in which agents find themselves involuntarily by providing reasons or directional guidance. Agents have an important role in understanding the interplay between structure and agency. To understand agency, we have to evaluate the context, beliefs, and ideas in light of agents' situations. In other words, the situations in which agents find themselves do not have a direct impact on agents, but are reflexively mediated via agents' concerns through the stance they take [5].

The morphogenetic approach, conceptualise the interplay between structure and agency over time in terms of analytical dualism, i.e., artificially separation between structure and agency. This helps us to analyse the interplay between digital materiality and agential reflexivity and explain how structure shapes action and social interaction, i.e., agency, and how agency changes, i.e., morphogenesis or reproduces, i.e., morphostatis, a given structure. Morphogenesis refers to "those processes which tend to elaborate or change a system's given form, structure or state" and morphostasis refers to "processes in a complex system that tend to preserve these unchanged" [4]. 
By employing the morphogenetic approach, digitalisation is conceptualized as a phenomenon that emerges from the interplay between structure and agency over time [5]. The analytical structure-agency dualism is operationalised employing a morphogenetic cycle that consists of three phases. The morphogenetic analysis starts at T1, structural conditioning, and covers the time span between the introduction of EPR system into the geriatric clinic and the emergence of digitalisation.

Structural conditions are present before the sociomaterial interaction and are the consequence of previous agents' actions. Reflective of T1, it corresponds to conditions before health care digitalisation (figure 3).

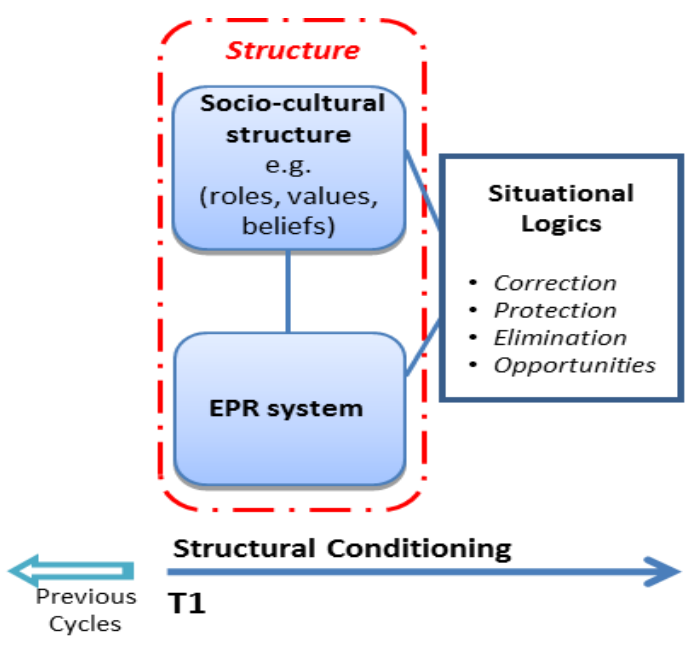

Figure 3. T1 Structural Conditioning

As a result of challenges, that thrust interrelated agents within a particular structure, relationships between socio-cultural (e.g. resources, roles, values, beliefs); and digital technology elements (e.g. IT infrastructure, content, processes and services) are activated. In this case, the available socio-cultural and technology elements and the combinations thereof are represented by an EPR system.

Along with the distribution of existing resources, socio-material configurations distribute vested interests by particular bargaining positions. The occurrence of relationships of necessary compatibilities, necessary incompatibilities, contingent compatibilities, and contingent incompatibilities within structures generates four situational logics: correction; protection; elimination; and opportunities. Situational logics motivate agents towards different courses of action, arising from compatibilities or incompatibilities between social interaction and EPR system interaction $[3 ; 6]$.
Between T2 - T3, agents respond to this conditioning through socio-material interaction. Once the EPR is implemented, agents take a stance towards the structural conditions that confront them and act in pursuit of their interests. For instance, they might seek to preserve or change their situations. They devote resources and pursue different changes through their actions and interactions with other agents (figure 4).

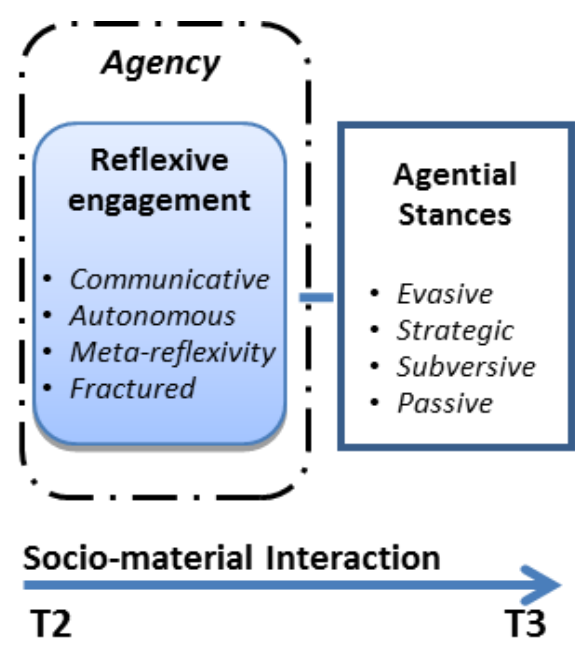

Figure 4. T2-T3 Socio-material interaction

Situational logics foster particular types of reflexivity and provide directional guidance by supplying reasons for distinct modes of integrating digital technology into health care operations. This represents the initiation of the health care digitalisation and sets up the conditions that subsequently trigger, or fail to trigger, the generative mechanisms of digitalisation. When interrelated agents use different modes of reflexivity to deliberate on their personal and relational concerns, they take particular stances towards the integration of digital technology into health care operations.

The first three modes of reflexivity: communicative, which adopt an evasive stance; autonomous, which adopt a strategic stance; and metareflexive, which adopt a subversive stance, indicate an active agent with a distinctive stance towards his or her situation. A fractured reflexivity produces a passive agent who lacks a stance towards his or her environment [5]. The different modes of reflexivity have clear consequences for the patterns of EPR integration and the socio-material configuration that are mobilised. This represents the emergence of digitalisation in health care settings. 
The last phase, structural elaboration at $\mathrm{T} 4$ is the effect of socio-material interaction from the previous phase. These interactions actualise the digitalisation of health care (figure 5).

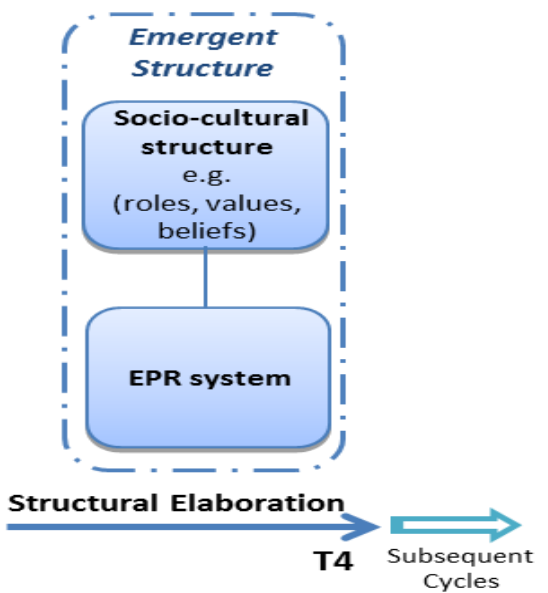

Figure 5. T4 Structural Elaboration

New socio-material configurations are characterised by particular forms of EPR integration and ways of organising. A distinct morphogenetic change is now evident.

Applying the morphogenetic approach as a framework for studying health care digitalisation highlights that digitalisation is a form of socio-material change generated over time by the interplay between (1) situational logics, which are delineated by sociomaterial configurations that provide directional guidance by enabling or constraining different modes of integration; and (2) agential stances, which are delineated by self-determined configurations of concerns outlined by different modes of reflexivity motivated agents to pursue different actions and interactions. This interplay explains the emergence of digitalisation as a morphogenetic process. The outcomes of one morphogenetic cycle are the start and socio-material conditioning of a subsequent cycle.

\section{Research setting and method}

To answer the research question and gain necessary insights to uncover the generative mechanisms of digitalisation we conducted an extensive longitudinal case study, which has been recommended for conducting critical realism research in general, and for identifying generative mechanisms in particular [20].

What makes critical realism and the morphogenetic approach of particular relevance for this study is their focus on providing explanations of change over time through the identification of the generative mechanisms.
A case study of a geriatric clinic in Jönköping County Hospital which was implementing an EPR system serves as the empirical basis. The hospital is internationally known having earned several national and international awards for health care quality [9; 29]. In 2009 Jönköping County decided to move from a paper-based patient records system to a standard offthe-shelf EPR system. We exploited this opportunity to study the digitalisation at the hospital's geriatric clinic as it was the first clinic to implementing the EPR system. Geriatric clinic housed three wards: Geriatric A (orthopaedic rehabilitating of patients with osteoporosis and fractures), Geriatric B (stroke care) and Geriatric C (dementia patients).

The study adopts a qualitative multi-method approach, which subsumes a combination of different qualitative data collection techniques for data collection: interviews, observations and field-generated documents. The first author completed 64 semistructured interviews in two phases: 33 interviews before and 31 interviews after the EPR implementation (Table 1).

\section{Table 1. Interviewed Geriatrics' personnel}

\begin{tabular}{|c|c|c|}
\hline & Phase 1 & Phase 2 \\
\hline & Manager & Manager \\
\hline \multirow{6}{*}{ Ward A } & Managers: & Managers: \\
\hline & Physicians: & Physicians: \\
\hline & Nurses: & Nurses: \\
\hline & Physiotherapist: $\quad 1$ & Physiotherapist: $\quad 1$ \\
\hline & Occupational therapists: 2 & Occupational therapists: 2 \\
\hline & Total 13 & Total 11 \\
\hline \multirow{6}{*}{ Ward B } & Managers: & Managers: \\
\hline & Physicians: & Physicians: \\
\hline & Nurses: & Nurses: \\
\hline & Physiotherapists: $\quad 2$ & Physiotherapists: $\quad 2$ \\
\hline & Occupational therapist: 1 & Occupational therapist: 1 \\
\hline & Total: $\quad 11$ & Total: $\quad 11$ \\
\hline \multirow{7}{*}{ Ward C } & Managers & Managers: \\
\hline & Physicians: & Physicians: \\
\hline & Nurses: & Nurses: \\
\hline & Physiotherapist: $\quad 1$ & Physiotherapist: \\
\hline & Occupational therapist: 1 & Occupational therapist: 1 \\
\hline & $\begin{array}{ll}\text { Counsellor } & 1\end{array}$ & $\begin{array}{ll}\text { Counsellor } & 1\end{array}$ \\
\hline & Total: & Total: \\
\hline Grand Total & 33 & 31 \\
\hline
\end{tabular}

The interviews lasted between $45-60 \mathrm{~min}$ and were audio-recorded. The respondents were asked about their perception, expectation and use of the EPR, and about what the EPR enabled or constrained them to do. The interviews were transcribed verbatim and sent back to the respondents for member checking. To complement and validate data from interviews, the first author spent 80 hours in each ward, 40 hours before and 40 hours after the EPR implementation, as a participant observer. He followed nurses on ward rounds, sat in on their meetings and observed their work practices. 
As the objective of this research was to explain how digitalisation emerges at the three geriatric wards the empirical material was subjected to cross-ward comparisons and causal analysis. Following Bergene [10], the empirical data were analysed in two phases. In the first phase, the analysis was concerned with the understanding of the context and pre-existing conditions of the digitalisation phenomenon.

We started by repeatedly reading the transcripts of the interviews and the observation notes. After we were familiarized with the contents, we abstracted the case through abduction and found both similarities and differences between these wards (table 2).

Table 2. Comparison and contrast

\begin{tabular}{|c|c|c|}
\hline & Similarities & Differences \\
\hline Ward A & $\begin{array}{l}\text { Management } \\
\text { - Rules } \\
\text { - Objectives } \\
\text { - Handovers } \\
\text { - Ward rounds } \\
\text { - Morning meetings } \\
\end{array}$ & $\begin{array}{l}\text { - Treat different patients } \\
\text { - The ward is set up differently } \\
\text { - Size } \\
\text { - Work processes }\end{array}$ \\
\hline Ward B & $\begin{array}{l}\text { - Management } \\
\text { - Rules } \\
\text { - Objectives } \\
\text { - Handovers } \\
\text { - Ward rounds } \\
\text { - Morning meetings } \\
\end{array}$ & $\begin{array}{l}\text { - Treat different patients } \\
\text { - The ward is set up differently } \\
\text { - Size } \\
\text { - Work processes }\end{array}$ \\
\hline Ward C & $\begin{array}{l}\text { - Management } \\
\text {. Rules } \\
\text { - Objectives } \\
\text { - Handovers } \\
\text { - Morning meetings }\end{array}$ & $\begin{array}{l}\text { - Treat different patients } \\
\text { - The ward is set up differently } \\
\text { - Size } \\
\text { - Ward rounds } \\
\text { - Work processes \& Routines } \\
\text { - Interaction with patients }\end{array}$ \\
\hline
\end{tabular}

The comparison and contrast made sense because the digitalisation outcomes were different. The cases also provided valuable opportunity to identify some generative mechanisms of digitalisation and to understand and explain causal conditions underlying different outcomes. The identification of generative mechanisms followed a five-step process for critical realist data analysis based on Bygstad et al. [14], (figure 6).

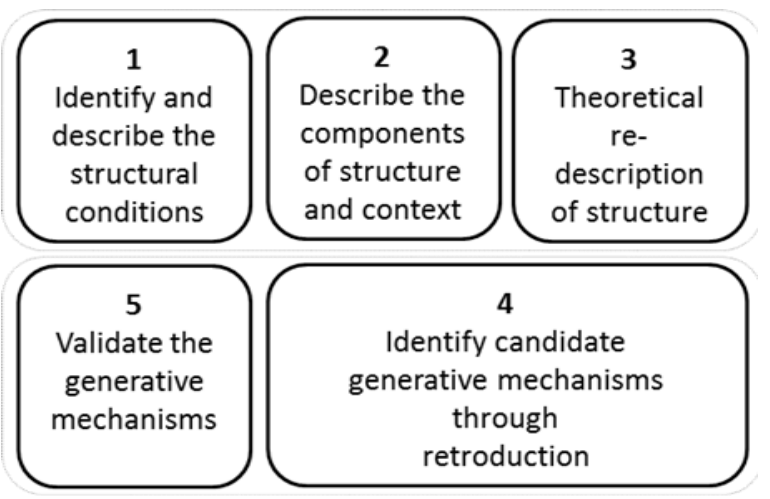

Figure 6. Framework for data analysis
We first analysed the data to identify and describe the structural conditions. Then, we identified and described the components of the structures and context. In the next step, we abstracted the case through abduction and after that we identified an approach to describe and explain the events. In the fourth step, we identified the generative mechanisms through retroduction, i.e., the reconstruction of the conditions necessary for a given outcome to occur. By analysing the interplay between social and material elements we then settled on three generative mechanisms of digitalisation, i.e., data-sharing, process-streamlining, and connectivity mechanisms. In the fifth and last step, we selected the generative mechanisms that best explain the emergence of digitalisation across the geriatric wards.

\section{Initial analysis}

Our analysis is still in progress; however, we have identified three generative mechanisms that to some extent might explain the emergence of digitalisation across the geriatric wards. These are the data-sharing, process-streamlining, and connectivity mechanisms.

Data-sharing mechanism, i.e., a process by which work practices are reproduced as a mandatory replacement of paper-based devices enables a digitalisation of patient records.

For instance, health care professionals have to type medical records into a standard format and use the same digital technology, i.e., screens, keyboard and mouse. This is reflective of standardised work practices. Activated, this mechanism should take away the need to record patient-related data on paper. However, the nurses at geriatric A, for example, continued to rely on paper to take notes during the ward round.

"The system cannot compensate the paper-based journal. As such, we continue to rely on paper. "(nurse)

Moreover, data-sharing mechanism should enable communication and organisational coordination through standard documents and data-sharing.

Accessing and using patient data depends on patient-related data being recorded, stored and made available through multiple devices, anytime and anywhere. If health care professionals used the EPR system to record new patient-related data promptly, thoroughly, and accurately, they enable visibility and transparency to patient trajectory through the health care system and cooperation across departments.

Process-streamlining mechanism, i.e., a process by which more personalised services are provided as a revision of work practice afford a visualised communication of patient-related information. For 
example, at geriatric $\mathrm{B}$ the ward round takes place at the physician's office. The patient visualises his or her medical data on a screen. Furthermore, the EPR replaced the daily meeting between the nurses.

"We don't have the traditional oral shift handover any longer. We have to bring our laptops to the office and read the reports there" (nurse).

By contrast, the nurses at ward A found that patient hand-offs were more efficiently made face-to-face and spoken communication rather than via computermediated texts.

"It's hard to get the same information about the patient by using the computer. Besides, you can't ask questions or ask for a piece of advice. So, for our patient safety, we still use oral handover" (nurse)

Connectivity mechanism, i.e., a process by which more services (e.g., care documentation, referral questions, health administration, resource planning) are supported as an increased interconnection of EPR's modules enable a shared information, communication and network platform. For example, physicians at geriatric $\mathrm{C}$ started to check the status of patient orders to ensure that patients received the care ordered.

"It's much easier to access patient data now. I can also follow my patients' trajectory through the health care system. Now I can see when the patient was for example at the surgical or medical clinic. I can easily obtain the information I need" (physician).

These three mechanisms feed on each other. Datasharing mechanism enables the process-streamlining, which in turn enables connectivity.

\section{Discussion}

As an explanatory framework, the morphogenetic approach provides not only a conceptual tool to describe and explain social change over time, but it also gives the opportunity to account for the relationship between structure (the materiality of technology); and how this may or may not effect agency (the different modes of agential reflexivity). For example, the framework suggested in this study include technology, i.e., has a material aspect, and help to interpret and contextualize digitalisation, and to provide descriptions and explanations that take into account that which contributes to the occurrence of digitalisation, the conditions under which is it occurring over time, and the intended and unintended outcomes. Additionally, the framework enabled the identification of generative mechanisms which helped us to explain the emergence of digitalisation at the geriatric clinic we studied.

\section{Conclusion}

While our candidate mechanisms are somewhat tentative, this research nevertheless makes some contributions. A contribution of this study (is) a midrange theory applying to digital technology, e.g., an EPR and its users, i.e., health care professionals. Understanding generative mechanisms of digitalisation is an issue of primary concern to policy makers and managers in health care, who are responsible for the introduction of an EPR system. The knowledge also helps them to develop recommendations for identifying and addressing EPR-related challenges.

IS research would benefit from insightful knowledge about the generative mechanisms of digitalisation as they are useful in understanding and explaining how digitalisation emerges. Understanding the conditions and the outcomes of an attempt to introduce new technology may assist IS developer in developing better solutions and design for EPR systems.

This research also finds evidence for the usefulness of critical realism for developing substantive contributions in the IS field. Specifically, it addresses a theoretical void in the IS literature that has limited our ability to study how the materiality of technology and agential reflexivity interact.

\section{References}

[[1] Abraham, C. and I. Junglas, "From cacophony to harmony: A case study about the IS implementation process as an opportunity for organisational transformation at Sentara Health care". The Journal of Strategic Information System (20:2), pp. 177-97, 2011.

[2] Agarwal R., G. Gao, C. DesRoches and A.K. Jha, "The Digital Transformation of Health care", Information Systems Research, (21:4) pp. 796-809, 2010.

[3] Archer, M.S., Realist social theory: The morphogenetic approach, Cambridge University Press, 1995.

[4] Archer, M.S., Morphogenesis versus Structuration: On Combining Structure and Action", The British Journal of Sociology (61:S1), pp. 225-252, 2010.

[5] Archer, M.S., Morphogenesis: Realism's explanatory framework, in Sociological realism, A. Maccarini, E. Morandi, and R. Prandini (eds.), Taylor \& Francis, pp. 59-94, 2011.

[6] Archer, M.S., How agency is transformed in the course of social transformation: don't forget the double morphogenesis, in Generative mechanisms transforming the social order, M.S. Archer (ed.), Springer International publishing, Switzerland, 2015. 
[7] Aron, R., S. Dutta, R. Janakiraman and P.A. Pathak, "The impact of automation of systems on medical errors: evidence from field research", Information Systems Research, (22:3), pp. 429-446, 2011.

[8] Avison, D., and Young T. 2007. "Time to Rethink Health care and Ict?," Communications of the ACM (50:6), pp. 6974 .

[9] Baker, G.R., A. MacIntosh-Murray, C. Porcellato, L. Dionne, K. Stelmacovich and K. Born, High performing health care systems, Delivering Quality by Design: An Examination of Leadership Strategies, Organisational Processes and Investments Made to Create and Sustain Improvement in Health care, Longwood's Publishing, Toronto, Ontario, 2008.

[10] Bergene, A.C. "Towards a Critical Realist Comparative Methodology: Context-Sensitive Theoretical Comparison", Journal of Critical Realism, (6:1), pp. 5-27, 2007.

[11] Berwick, D.M. "A user's manual for the IOM's 'Quality Chasm' report”, Health Affairs, (21:3), pp. 80-90, 2002.

[12] Bhaskar, R., A Realist Theory of Science, Harvester, Hemel Hempstead, UK, 1978.

[13] Braithwaite, J., W.B. Runciman and A.F. Merry, "Towards safer, better health care: harnessing the natural properties of complex sociotechnical systems", Quality and Safety in Health Care, (18:1), pp. 37-41, 2009.

[14] Bygstad, B., B.E. Munkvold and O. Volkoff, "Identifying Generative Mechanisms through Affordances: A Framework for Critical Realist Data Analysis," Journal of Information Technology (31:1), pp. 83-96, 2015.

[15] Car, J., A. Black, C. Anandan, C.K. Cresswell, C. Pagliari, B. McKinstry and A. Sheikh, "The impact of eHealth on the quality and safety of health care", A Systemic Overview \& Synthesis of the Literature Report for the NHS Connecting for Health Evaluation Programme, 2008.

[16] Carlsson, S.A., The Potential of Critical Realism in IS Research, in Information Systems Theory, Y.K. Dwivedi, M.R. Wade, and S.L. Schneberger (eds.). Springer, New York, pp. 281-304, 2012.

[17] Dobson, P., "The philosophy of critical realism - an opportunity for information systems research", Information Systems Frontiers, July, 2001.

[18] Edwards, P., J. O'Mahoney and S. Vincent, (eds.), Studying Organizations using Critical Realism: A Practical Guide, Oxford University Press, Oxford, 2014.

[19] Elster, J., Explaining Social Behavior: More Nuts and Bolts for the Social Sciences, Cambridge University Press, Cambridge, 2007.

[20] Easton, G., "Critical realism in case study research", Industrial Marketing Management, (39), pp. 118-128, 2010.
[21] Fichman, R.G., R. Kohli and R. Krishnan (eds.), "Editorial overview-the role of information systems in health care: Current research and future trends", Information Systems Research, (22:3), pp. 419-428, 2011.

[22] Fonkych, K. and R. Taylor, The State and Pattern of Health Information Technology Adoption, CA: RAND Corporation, Santa Monica, 2005.

[23] Goh, J.M., G. Gao and R. Agarwal, "Evolving work routines: Adaptive routinization of information technology in health care", Information Systems Research, (22:3), pp. 565585,2011 .

[24] Han, Y.Y., J.A. Carcillo, S.T. Venkataraman, R.S. Clark, R.S. Watson, T.C. Nguyen and R.A. Orr, "Unexpected increased mortality after implementation of a commercially sold computerized physician order entry system", Pediatrics, (116:6), pp. 1506-1512, 2005.

[25] Hanseth, O., Integration-complexity-risk: the making of information systems out-of-control, in C.U. Ciborra, and O. Hanseth (eds.), Risk, complexity and ICT, Edward Elgar, Oslo, 2007.

[26] Hebert, M.A. "Impact of IT on health care professionals: changes in work and the productivity paradox", Health Service Management Res. (11), pp. 69-79, 1999.

[27] Henfridsson, O. and B. Bygstad, "The Generative Mechanisms of Digital Infrastructure Evolution", MIS Quarterly, (37:3) pp. 907-931, 2013.

[28] Jadad, A.R. and T. Delamothe, "What next for electronic communication and health care?: New tools that require new thinking”, BMJ: British Medical Journal, (328:7449), pp. 1143, 2004.

[29] Kenny, C., The best practice: How the new quality movement is transforming medicine, USA, 2008.

[30] Krog, A.B., Formidlingsrapport från Ph.D.-projektet Förhandlingar om patienten-den elektroniske patientjournal som kommunikationsmedie, Syddansk Universitet, Institut for Litteratur, Kultur og Medier, 2009.

[31] Leonardi, P.M., "Theoretical foundations for the study of sociomateriality", Information and Organization, (23:2), pp. 59-76, 2013.

[32] Mingers, J., A. Mutch and L. Willcocks, "Critical realism in information systems research", MIS Quarterly, (37:3), pp. 795-802, 2013.

[33] Mutch, A., "Technology, Organization, and Structure A Morphogenetic Approach", Organization Science, (21:2), pp. 507-520, 2010.

[34] Mutch, A., "Sociomateriality - Taking the wrong turning?", Information and Organization, (23:1), pp. 28-40, 2013. 
[35] Orlikowski, W.J. and C.S. Iacono, "Desperately seeking the "IT" in IT research: A call to theorizing the IT artifact", Information Systems Research, (12:2), pp. 121-134, 2001.

[36] Orlikowski W.J. and S.V. Scott, "Sociomateriality: Challenging the Separation of Technology, Work and Organization", The Academy of Management Annals, (2:1), pp. 433-474, 2008.

[37] Randeree, E., "Exploring physician adoption of EMRs: a multi-case analysis", Journal of medical systems, (31:6), 489496, 2007.

[38] Sayer, A., Method in Social Science: a Realist approach $\left(2^{\text {nd }}\right.$ ed.), Routledge, London, 1992.

[39] Sayer, A., Realism and social science, Sage, U:K: 2000.

[40] Sherer, S.A., "Information Systems and Health care XXXIII: An Institutional Theory Perspective on Physician Adoption of Electronic Health Records", Communications of the Association for Information Systems, (26:1), pp. 127140, 2010.
[41] Tilson, D., K. Lyytinen and C. Sørensen, "Digital Infrastructures: The Missing IS Research Agenda", Information Systems Research,(21:5), 20th Anniversary Special Issue of Emerging Challenges, 2010.

[42] Westbrook, M.T., J. Braithwaite, J.F. Travaglia, D. Long, C. Jorm and R.A. Iedema, "Promoting safety: Varied reactions of doctors, nurses and allied health professionals to a safety improvement program", International Journal of Health Care Quality Assurance, (20:7), pp. 555-71, 2007.

[43] Yoo, Y., K.J. Lyytinen, R.J. Boland and N. Berente, "The Next Wave of Digital Innovation: Opportunities and Challenges: A Report on the Research Workshop' Digital Challenges in Innovation Research", Available at SSRN 1622170, 2010a.

[44] Yoo, Y., O. Henfridsson and K. Lyytinen, "Research commentary-The new organizing logic of digital innovation: An agenda for information systems research", Information Systems Research, (21:4), pp. 724-735, 2010b.

[45] Yoo, Y. "The Tables Have Turned: How Can the Information Systems Field Contribute to Technology and Innovation Management Research?", Journal of the Association for Information Systems, (14:5), pp. 227-236, 2013. 